\title{
The Effect of Learning Situations Problems on the Performance and Procedural Attitudes in Judo: The Example of the Pupils of the School Centers for the Promotion of Judo in Tunisia
}

\author{
Chokri Naffeti ${ }^{1}$, Nejah Kacem ${ }^{2}$, Ayman Guemri ${ }^{3}$, Mourad Bahloul ${ }^{4}$ \\ ${ }^{1}$ Higher Institute of Sport and Education Physics of Sfax, Sfax, Tunisia \\ ${ }^{2}$ Group for the Study of Development and Social Environment (GEDES), Faculty of Human and Social Science of \\ Tunis, Tunis, Tunisia \\ ${ }^{3}$ State, Culture and Change of Society, Higher Institute of Sport and Education Physics Ksar Said, Mannouba, \\ Tunisia \\ ${ }^{4}$ Higher Institute of Business of Sfax, Sfax, Tunisia \\ Email: kacemnejah@gmail.com
}

Received 24 May 2016; accepted 8 August 2016; published 11 August 2016

Copyright (C) 2016 by authors and Scientific Research Publishing Inc.

This work is licensed under the Creative Commons Attribution International License (CC BY). http://creativecommons.org/licenses/by/4.0/

(c) (i)

Open Access

\begin{abstract}
Acquiring knowledge in situations of learning depends on the competence of the Tunisian Judo student's promotion to develop new mental structures. In terms of education, it is necessary to operate a real pedagogical progression to accompany the student in the building of his own knowledge. Within this framework, the difficulty of the judo teacher is double. Firstly, it is necessary to carry out a detailed analysis of the initial knowledge of his students and on the other hand, it must implement the pedagogical situations adapted to the rated level. This article sheds light on the study of the effect of learning on knowledge in judo among students based on situation problem. To apply these methods, we took the didactic organization and epistemological activity following its internal logic in order to highlight the modifications and design changes in the learner. To achieve these goals, we resorted to an experiment conducted on three groups: each one practices Judo by one of the three methods of learning.
\end{abstract}

Keywords

Learning Situation Problem, Procedural Attitudes, Performance, Centre for the Promotion of Judo 


\section{Introduction}

Throughout their education, students should acquire knowledge. Today, the problem of knowledge lasts from 15 to 20 years. The knowledge acquired is diversified and numerous. Some is more and more specialized in a particular disciplinary field forming the basis of future professional competencies; some will become general knowledge; others will be apparently forgotten. This debut issue brings a didactic reflection on the teaching of judo, its objectives and its challenges. Indeed, how to be sure that the student has understood and learned that knowledge affects him. How to be sure that education is suitable for the student. A lot of work is done in physical and sports Education (EPS) and laying work on the teaching of certain APSA (swimming, athletics, collective sports etc.). Some work is focused on the teaching of combat sports and in particular on judo such those of Loizon, Margnès, \& Terrisse (2004). Most of them have pedagogic objectives: (Bresciani et al., 1963; Inogai \& Habersetzer, 1985) or have been conducted comprehensively from the psychological and sociological theories. Other research is focused on judo teaching at the elementary school on the didactic transposition (Bresciani, 1984; Margnes, É, Loizon, D, \& Terrisse, A, 2008; Terrisse, 1996) on the evolution of the ratio of force (Collinet, 1992); on the construction of the contents of education of judo (Janicot, 1985; Bush, 1991). In the book led by A. Terrisse, an important part regarding the didactics and pedagogy of martial arts and combat sports is found (Terrisse, 2000). In addition, M. F. Carnus and A. Terrisse justify "significance and the use of the methodology of didactic engineering in the analysis of decisions of students in situations of opposition in Physical Education and sport" (Carnus, 2007; Terrisse, 2002). In the thesis, Loizon et al. (2004) analyzed teaching in judo practice and pondered the knowledge actually transmitted by the teachers club and EPS. The conclusion of this work shows knowledge of a very different nature transmitted in these sessions. It reflects that the comprehension of the judo's teaching goes through "filters", which are for the researcher means of analysis decisive in its professional practice. The thesis of Eric Margnes is related to the knowledge of analysis transmitted in judo by two trainers: "Didactic intention in teaching judo, cultural choices of ethical and technical order. Case study on the teaching situations-their staging for beginners in the initial training of STAPS” (Margnes, 2002). The interest of this work lies in its successful attempt to establish a grid of analysis of this activity, differentiating two conceptions of judo and two modes of treatment of this activity. There is no research on the apprenticeship in situations of combat in judo which marks the subject of our investigations. The originality of our research lies in the fact that it is related to learning judo in schools of promotion in Tunisia and it would be carried out from the application of the situation problem as a pedagogic means and their impact on the students' knowledge. The objective of this study is to identify the effects of the methods of learning (with situation problem, analytical and combined) on the acquisition of performance in judo among students in the promotion of judo school.

\section{Theoretical Framework}

Speak of location problem, is to report a field of application or environment, with real actors and specific purposes; Therefore the existence of a situation that gives full meaning to learning. The problem situation constitutes a very important didactic concept that overlaps both the logic of learning, disciplinary logic and cultural logics. It is a situation of research for the student, which implies a to-do (problem) that the student can succeed through some tools. It would be unfair not to mention. Cornu and Vergniaux (1992) for which the problem situation is a learning situation that is designed in such a way that students cannot solve the question by mere repetition or application of knowledge or skills and such that it requires the formulation of new hypotheses. It is for them a model of education that is characterized by the following facts: Motivation, curiosity raises a question, the student in a situation of construction of knowledge, the structure of the task allows each to implement and perform mental operations required by the purpose of learning, the student is evaluated in its personal acquisitions. At this level the expression "situation problem" (Amade Escot (1989)) characterizes a concrete situation that raises questions. When the problem situation takes a multidimensional character, it is likely to be dealt with inter-disciplinary. Moreover, it allows one hand to create in students a space for reflection and analysis around a problem to solve or an obstacle to be overcome. On the other hand, construction of knowledge, finally it ensures a pedagogical integration function insofar as its representation can mobilize various skills and knowledge by integrating. Certainly, the problem used during the apprenticeship situation can be fully resolved with what already mastered students, but these acquisitions will help the learner to analyze, explore the different approaches of attempts at solutions, compare them between them to raise new issues. In this connection, recourse to a problematic situation undoubtedly meets the three major educational functions by Astolfi (1997) who says the prob- 
lem situation: is a mobile learning: it allows controlling the pupil during functional activities; it is a way of learning that allows the appropriation, the student of knowledge and skills in the context of the resolution of a problem open and complex or the completion of a task. It provides a criterion for evaluation of learning: serves as a check, at the end of a sequence of learning if students are well appropriate knowledge or competences referred. Roegiers (2000) reports that a problem situation is a significant situation that engages the learner and which gives him the desire to get in motion conferring a sense what he learns. The educational ideal located the proposed issue for each of the students of the class, seeking, in the words of Vygotsky (1985); in the "proximal zone of development" where learning processes must take place. The latter defines the (ZPD) wisely: "it's the difference between the level of resolution of problems, edited with the help of adults and that reached by the child alone", we see well that experience shows that a situation of learning established by the training is rarely optimal for all students without distinction: they do not address situations with the same resources and meet the same obstacles. In the context of Perrenoud (1999) "a standard situation can only exceptionally be optimal for all (students), because they do not have the same level of development, the same prior achievements, the same report to knowledge, the same interests, the same means and ways of learning”. In the field of physical education and sports, Marsenach and Amade-Escot (1993) consider that the problem situation must retain, meaning knowledge; this is a real difficulty today as EPS, or, under the pretext of simplification, it completely purifies the content. In addition, Amade-Escot (1989) thinks that a problem-solving situation must have three characteristics "that result in a cognitive activity of information; to enable adaptive decision-making choices; to operate an” optimal offset promoting the emergence of new lines. The student then built his knowledge in an experiment: he "learns in the interaction of action and reflection. Two key concepts are developed by cognitive psychology to account for the acquisition of knowledge. It comes to notions of situation of problem solving and prior knowledge. However, the acquisition of knowledge in cognitive psychology, is inseparable from the notion of resolution of a problem situation. It would be above all in resolving issues that the student would have to structure or restructure its representations and thus acquire new knowledge. According to Richard (1997), a problem can be defined as" a task at hand under defined conditions and for which it is not embodiment in these terms: we know what is the goal, we know the context in which it is to be achieved, but is unknown procedure to achieve it. Similarly, Cauzinille-Marmèche (1996), says that is a problem the student as soon as there is a gap between a current situation and purpose sought to be achieved. Any school activity a student can be, in the same way, designed as a problem solving activity. whether it actually solve a mathematical problem or respond in English to the promptings of the language teacher. Whatever the problem, it is always sets by an initial state (the data of the problem), a final State (the goal) and a succession of actions (actual or mental) that we can appoint procedure and which will "take" from the initial state to the final State. A problem is then to develop strategies to implement procedures to connect the initial state to the final State. Richard (1998) thus lists three types of problems through: discovery of rules and relationships problems occurring in situations of diagnosis, problems of transformation of States. Thus, it is clear that the student to be able to solve at best all situations-problems that occur to him, must be able to use all the knowledge essential to the smooth running of these resolutions. In the reverse case, i.e. If no knowledge may be convened to resolve the issue, it is likely to remain whole and insolvent. In fact, a second concept, often associated with that of problem solving, is paramount in cognitive psychology: it's prior knowledge According to Ausubel (1968), which was one of the first to develop a cognitive model of the acquisition of knowledge applied to education, "the most important of the factors influencing learning is what the student already knows. However, for cognitive psychology, learning is not simply to collect information and/or stack knowledge: it is necessary to understand for learning. The previous knowledge in a given field are essential to the learning process because they represent a "cradle" to accommodate new knowledge inherent in this area. In fact, information that could not be "connected" to any prior knowledge becomes relevant and information stored by the cognitive System. In other words, the integration of new information into long-term memory depends on the efficiency of previous knowledge to which it is possible to relate new information. Pedagogically, the teacher must "deconstruct" his disciplinary knowledge largely automated to do so that the student can reconstruct these disciplinary knowledge. These necessities and possibilities of adaptation of an expert to the novice, have been particularly well described by the Russian psychologist Vygotsky (1896-1934), through the concept of Proximale Development Zone “ZPD” Vygotsky (1985) this area can be defined as the difference between what the adult (the teacher) knows and what the child can understand; it means acquire on the basis of previous knowledge and its level of development. This is most commonly the area of progress of the student in which the intervention of the teacher should be. In terms of cognitive psychology, it is specifically, provide new 
but relatable information by student prior knowledge. Without this possible link, it is likely that the student can really' give meaning "to these information and activity which they emanate. It may not actually build its knowledge. From the point of view of cognitive psychology, the acquisition of knowledge is not the result of a single activity mental, clearly identifiable, but is based, instead, on the articulation and coordination of various cognitive activities. Thus, according to Richard (1998), learn suppose to be able to implement activities, among other things, understanding, building of conceptual structures in long-term memory through selective and strategic memorization process. to treatments inferential based on prior knowledge, to develop and test hypotheses, to generalize knowledge or to recognize the class of a problem.

Two different contexts of knowledge construction can be distinguished. In one case, a student can be confronted with an entirely new problem situation whose resolution cannot be directly ensured by recourse to previous knowledge directly for the trafficking problem. In this case, it is for the student to begin the construction of a new field of knowledge. In either case, the problem situation can be linked to prior knowledge. It is then less for the student to construct new knowledge to deepen or enhance a domain of knowledge preexisting. When it comes to building a new field of knowledge, the essential challenge for the student is to initiate the incorporation of new knowledge or representations in the absence of previous knowledge directly relevant. It is a problem situation that frequently goes to meet the student whenever a new concept is introduced by the teacher. Two responses are made by cognitive psychology attempt to explain this "switching" mechanism: recourse to General rules on problem solving (GPS) and the use of the analogy one way from (try of) resolve an initially unknown problem situation is to resort to rules very general problem solving. It comes to carry out explorations, trial and error, of trial and error, and, specifically, to implement strategies of generic resolutions which could be applied to any type of problem. These strategies, named (GPS) (English: General Problem Solver) by Newell and Simon (1972), can sometimes be complex. Certainly, in judo learning is based on the action which involves to discover, to memorize the steps in solving a problem while trying to understand the principles and operation. The interest of the action learning is confront the student with a problem whose resolution is based on its activity even. This student will have to implement procedures for exploration, of trial and error, trial and error which will enable him to identify the nature, the extent of the problem. The important point is that the student will receive and have to consider positive or negative feedback from the problem situation. He can act, observe the result of its action, and infer rules of action recording can be done and should not be done. It is common that this mode of learning be adopted by science teachers who are going to introduce a phase of exploration and discovery during practical work. However, the learning by doing essentially causes the development of knowledge on the procedures necessary for the realization of a task or activity, but not necessarily knowledge referring to the function, objectives or the justification of this task. Thus, according to Shae Shae (1994), know-how, is not only to understand a procedure, it is also be able to evaluate it on the basis of the task and the functioning of the system; understand the meaning and effectiveness. This mode of learning through action and discovery presents a certain danger if the teacher ensures not to somewhat "theorize" by the student the procedural knowledge he was able to acquire during the exploration phase. Otherwise, such procedural knowledge can be understood as constituting a single procedure non-decomposable to resolve a problem. It is a recipe that will be consistently applied. This recipe can make a fortune as long as the exercise lends itself to its use, but the student will be quickly in situations of failure if the data of the problem is slightly different... Understand, however, how and why a recipe works, identify the interests and limits, amounted not to apply as a whole but to decompose this procedure in a series of sub-goals, or even of elementary to perform actions in including the reasons. It is certainly this condition that learning through action and discovery can prove effective. Didactics is that students are not the boxes empty, but they participate in the construction of their learning on the basis of school extra diffuse previous knowledge and on the basis of analysis and structure of the new information next to its permanent knowledge. Learning is considered to be an exploratory research of new behaviors driven by dynamic laws and not by memory research procedures illustrating the traditional conception of learning. Learning is thus defined by the construction or the stabilization of behavioral attractor State (Zanone \& Kelso, 1992) that satisfies the purpose of the task, and which sets the expert coordination. In addition, the emergence of the expert behavior is designed as discontinuous and nonlinear. This discontinuity can be assessed by analysis of the qualitative evolution of behaviour. Starting from this principle, the classic design of a continuous learning with performance at the centre of the process, cannot be generalized to the field of the evolution of motor coordination.

A motor skill learning: when we speak of motor learning, necessarily refers to motor skills. These are the purpose of learning. The concept of skill can actually be applied to any human activity directed towards a goal. 
Guthrie (1957) defines the ability as "ability acquired by learning to achieve results fixed in advance with the maximum of success and often a minimum of time, energy, or both". For Durand. M. (1987) "is an ability to resolve" a specific engine problem", to develop an effective and economic response to achieve a specific objective." This ability is acquired. "Also it is necessary to distinguish between movement/driving action and skill. The driving action is a movement (gesture) a purpose or spot (while the gesture may exist for him even), it becomes skill when it is carried out efficiently and effectively. Similarly, a skill contributes to the achievement of a performance based on a pre-established and this purpose with the minimum energy cost (efficiency) and requires the automation which is an adapted this behavior which demonstrates that if the skill is specific to the individual, it is in close contact with the relevant APS and its technique. It is therefore possible to say that the objective of the EPS is to allow the acquisition by the student of certain skills, corresponds to search better technical control Loma and Pailhous (1981), in their reflection on cognitive conditions of fiscal and the sensorimotor skills acquisition, characterize a gestures to the high level of his organization and define skillful performance following the following criteria: speed, fluidity and stability for Jonnaert (2008) "development and consistency of the response, smoothness of action, focus on results, improvements in execution speed these are the indicators expressing the fact that skill is automated, meaning that the subject can perform the task cost-effectively attentional or that his attention is directed toward other aspects of the task". In EPS and sport, what you are looking for is the acquisition of motor skills and this acquisition is manifested by the automation of the gesture. In this type of learning processes the acquisition of athletic skills must support smart learning with sufficient mental participation where the spirit must be creative and imaginative. On the other hand, closed skills are characterized by stable and certain environmental conditions. Learning processes must be those of the repetition of the conditioning to improve performance. These two types of skills constrain differentiated information processing system. Open skills often require a perceptual and decisional, activity under time pressure. However the skills closed assume comprehensive advance planning of action is possible. Certainly, remarkable level of sporting results in particular in recent years is the result of all the factors which the interaction affects the performance. In EPS teaching the concept of performance is linked to the concept of efficiency of training progress. Cazorla (1989) "whatever the sporting activity concerned the performance is always determined by the interaction of the following components: psychological, physiological, biomechanical and sociological." This indicates that performance covered by each athlete is essentially the product of these components in the sporting sense. Similarly, it is proposed a sporting activity and we wish the student achieves the best possible performance Malcuit \& Pomerleau (1977) argue that "performance is a measure of the behavior expressed by an agency after a condition given the environment and the body." Salgado (2013) adds that the motor performance is considered an indicator of the level of acquisition on the other hand, Famose and Durand (1988) believe that the notion of performance lies within an event sequence that is at the center of what is nome generally: task, activity, the result. It is by a more accurate development of the activity task that can attempt to clarify the meaning of the various terms mentioned and specifically defines the performance which is according to these authors as "a result, product activity, collected, measured and assessed by the practitioner or an outside observer”. Herbrard (1986) tells us that "the performance depends on learning level, i.e. of the State where the student is in transformations, in the coherence and effectiveness of its driving organization compared with the task at a given moment in its learning. It also depends in part on the level of skill of the subject in the task at hand. This skill level reveals essentially the at least greater ownership of the gestural technique known as favourable to activity or to the achievement of the task. However, when learning, a student can reach a good level of skill without that insofar this translates into superior performance. We therefore distinguish the difference between skill and performance. The notion of performance is often used interchangeably in the world of the APS and often changes depending on the authors. However, there is often different qualifications pursuant to (cognitive performance, motor performance, athletic performance, etc.). This study will be limited to the effects of learning by location problem on that procedural as well declarative knowledge, procedural attitude and performance during the practice of judo Sports orientation of current judo should not hide the essence of the practice. Despite their differences, the successive generations of judoka agree not to reduce their activity to a simple search of performance (Inokuma \& Sato, 1986; Baudot, Pelletier, \& Urvoy, 1975). The same educational goals are shared by the school judo and the clubs. In its entirety, the judo considers the confrontation as a training tool of the character and the body, and not as a single purpose. Attention to the ethics of combat allows as well as the expression of the will to defeat each be developed while preserving the mutual respect. When he joined the school, judo remains subject to this "technical" teaching design; in fact, there is little taught. The specificity of the context of school education (volume of low education, 
limited training of teachers, technical representation of the activity) of this activity seems, so endorsing simplifications suggested in the didactic proposals concerning the teaching of judo: "access to a global form of real combat from judo, with students who don't practice them in EPS” is impossible (Baker, 1996). Also, the current didactic proposals appear to move towards an alternative between two types of educational option, that we will develop: a dual option: Baker is campaigning for "a culturalized and contextualized EPS" (Baker, 1996). He does retain, as a learning object "gripping combat sports", that construction of the guard and the use of the strength of the opponent in a fight. To account for the goals of learning and results in cooperation and opposition, he chose two evaluation referring to "historical conceptions of judo" situations: the witnesses of a "do with knowledge" and the randoris kata characterizing the "know-how against". Similarly, judo involves the level of proficiency is assessed in the context of the opposition. However, if combat remains the core activity, the purpose of judo is not in domination of the opponent but, on the contrary, the best knowledge and dominance of oneself. The perspective of the educational struggle perceives in interest that represents the search for results. The requirement of education must focus on the individual student's commitment and a self-transcendence which cannot be reduced to the mere obtaining of victories in a framework dictated by a sporting regulations evolving. Inogai and Habersetzer (2002) report that the aims of education of judo are defined mainly by: the acquisition of specific techniques, individual adaptation to the evolution of the balance of forces, the affirmation of self-confidence and mastery of emotional factors. Motor, affective and intellectual student resources are thus requested to a realization of itself through situations of confrontation. Knowledge of technical, strategic or ethical education is essential for judo teachers (Loizon, Margnès, \& Terrisse, 2004). Knowledge identified through the implementation of the educational variables by these professionals in the teaching of judo are the bedrock foundation of the activity.

\section{Materials and Methods}

All concerned in our research subjects group is composed of students of primary education (6th year) belonging to the centre for the promotion of judo road to SOUKRA (Sfax). Selected students are aged 12 and are divided into three groups of 30 students with the following form:

A first group of 30 students aged 12 years 1 ) learns judo by the method of situation problem during the sessions throughout the experience.

A second group of 30 students aged 12 years 2) learns judo by the analytical method during the sessions throughout the experiment.

A third group of 30 students aged 12 years 3 ) learns judo by the method combined during the sessions throughout the experiment.

1) Measuring tools

Tests in our research are designed in the official program and the educational objectives of school promotion centres. Similarly, the tests are constructed by reference to tasks aimed at students of 6th year primary school centres for the promotion of judo program, published by the Directorate of physical education in collaboration with the Ministry of sport and physical education of Tunisia (2014).

2) Events of evaluation

For the sake of rigour and a litmus test of the different selected tests, we conducted a pre test.

This procedure was applied to a small sample of three groups of 5 students each. As a result, some changes in the Organization of the execution of the tests have been made:

Students were informed of the purpose and the Protocol of each test.

After the train, students spend motor performance tests, then those of the demonstration of gesture (procedural attitudes).

3) experimental protocol

The experimental protocol allows us to determine the effects of each of the methods of learning: with situation problem, analytical and combined, on the knowledge among students in schools for the promotion.

To achieve properly the objectives of this study, we considered it appropriate to begin with a diagnostic evaluation in advance for the groups to our experience. Accordingly, all subjects underwent tests meadows which focused on performance, procedural attitudes (see Table A1).

These same tests will be conducted at the end of the cycle of learning judo. This cycle extends over twelve weeks of teaching for two hours per week. During this experimental period of education which takes place 
within the ordinary course of promotion centre, each group is taught with a single method: either by location problem, or analytical. Either by the combined method. The contents of the three methods is based on the following form:

For education of the group learning judo by the analytical method, learning of technical elements is distributed throughout the period of teaching. The gesture of judo is broken down into key technical elements set out as phases of reversal in judo standing: preparation phase, execution, and the fall. Each of these phases is learned alone and apart from other elements.

For education of the group learning judo by the method of situation problem, learning the techniques is conducted simultaneously on the situation of opposition movement, and each student trying to learn and at the same time correcting all the elements to each teaching session.

For the teaching of the group learning judo by the combined method learning techniques is carried out on two-stroke: the gesture of judo is broken down into technical elements then it is performed simultaneously on movement.

Step 1: procurement of a pre-test to students of the three experimental groups (procedural attitudes and performance).

-Gexp1: (app. with situation problem).

-Gexp2: (app. analytical).

-Gexp3: (app. combined).

Pre-test registration.

2nd stage: Execution of a cycle of 12 sessions of learning for each group following the Organization of our experience.

-Registration of learning different sessions.

3rd stage: execution of a post-test to students of the three experimental groups (procedural attitudes and performance).

4th step:

-Observation of the individual behaviours of students, attack (TORI) and defence (UKE).

-Observation of the resolution of the task problem for students in attack and defence.

-Identify the different indicators depending on the behavior of students on an individual level.

4) measurement indicators

Our research is to identify the effect of learning with situation problem on standing judo for this knowledge, we used four such dimensions as "Table 1".

Acquisition expected by TORI: projected the opponent on the back using knowledge to solve a situation problem in standing judo familyas “Table 2".

\section{Results}

Consideration of improvement of each group to different designs and performance, depending on the learning method used:

To assess improvement concerning the different designs and performance in each group (relative to itself), due to the use of a method of learning during a school year in judo, we proceeded to the calculation of the Student's " $t$ " paired.

The results of Student's t show that according to the method of learning used, some variables of learning improve, within the same group, against other variables:

Practice of judo by the situation problem method to improve both procedural attitudes and performance.

Table 1. Degree of acquisition and assessment scale. Example of sheet individual observation of the students of the centre for the promotion of judo (in judo standing).

\begin{tabular}{cc}
\hline Degree of acquisition & Assessment scale \\
\hline$(-):$ Without achievements & $(-): 2$ \\
$(+):$ Minimum acquired & $(+): 4$ \\
$(++):$ Delete minimal achievements & $(++): 6$ \\
$(+++):$ Maximum gains & $(++): 8$ \\
\hline
\end{tabular}


Similarly, significant progress in procedural attitude stemmed mainly from the very significant progress registered in attitudes in preparation phase and phase of fall as "Table 3" (respectively p \& lt; 0.0001 and p \& lt; $0.001)$.

Learning by the combined method supports a very significant improvement in performance and procedural attitudes in group learning by the analytical method, noted improvements show highly significant performance (thanks to knowledge of a technique). However, regarding procedural attitudes, no not there was significant improvement. However, if it is logical that a variable performance can improve under the effect of a learning method, it is no less true that the degree of improvement, may vary as a result of one method over another. This invites us to check which of the three methods of learning the best effect on performance. The results of this comparison are as follows:

Performance: Judo Average statistical data of students belonging to the three groups of study at the level of the performance in judo are reflected as "Table 4":

With regard to the "Performance", the ANOVA showed:

$\square$ a significant 'Method' effect [F (2; 87) = 9.95; p \& lt; 0.001]; H2 $=0.186$

$\square$ a significant "learning" effect $[\mathrm{F}(1 ; 87)=209,52 ; \mathrm{p} \& \mathrm{lt}$; 0.001]; H2 $=0.707$

$\square$ a significant "Method X learning" interaction [F $(2 ; 87)=3.14 ; \mathrm{p}=0.048] ; \mathrm{H} 2=0.072$

The results shown in the table above through ANOVA calculation which reveals a $(\mathrm{F}(2 ; 87)=9.95$; p \& lt; 0.001 at the level of the effect of the method, F $(1 ; 87)=209,52$; p \& lt; 0.001 at the level of the effect of learning and $\mathrm{F}(2 ; 87)=3.14 ; \mathrm{p}=0.048$ to the level of the effect of the interaction method and learning demonstrated a significant difference that emerges between the three experimental groups on the one hand), we are seeing, a

Table 2. Acquisition expected by TORI.

\begin{tabular}{|c|c|c|c|c|}
\hline \multirow{3}{*}{$\begin{array}{l}\text { Rated } \\
\text { Method }\end{array}$} & \multicolumn{4}{|c|}{ Degree of acquisition } \\
\hline & $\begin{array}{l}\text { Without } \\
\text { acquis }\end{array}$ & $\begin{array}{c}\text { Acquis } \\
\text { minimum }\end{array}$ & $\begin{array}{c}\text { Acquis } \\
\text { SUP-minimal }\end{array}$ & $\begin{array}{c}\text { Acquis } \\
\text { maximum }\end{array}$ \\
\hline & $-(2)$ & $+(4)$ & $++(6)$ & $+++(8)$ \\
\hline Indicators & $\begin{array}{l}\text {-No projection } \\
\text { projection of } \\
\text { UKE stomach } \\
\text {-Lack of speed }\end{array}$ & $\begin{array}{l}\text {-Screening of UKE } \\
\text { without respected the } \\
\text { principles of attack } \\
\text {-Slow projection }\end{array}$ & $\begin{array}{l}\text {-Projection of UKE with the final } \\
\text { phase of waterfall continuity with } \\
\text { the absence of one of the } \\
\text { principles }\end{array}$ & $\begin{array}{l}\text {-Rapid projection of UKE with } \\
\text { the final phase of waterfall } \\
\text { continuity respecting the } \\
\text { principles of attack }\end{array}$ \\
\hline
\end{tabular}

Experimental group

Percentage (\%)

Table 3. Statistical values concerning procedural attitudes and performance according to the method applied in subjects in 3 groups.

\begin{tabular}{ccccc}
\hline & Methods & Before & After & $\Delta$ (Before-after) \\
\hline \multirow{2}{*}{ Procedural attitudes } & GMA & $4.48 \pm 0.93$ & $4.79 \pm 0.7$ & $0.32 \pm 1.25$ \\
GMSP & $4.61 \pm 0.63$ & $5.6 \pm 0.91^{* * *}$ & $0.99 \pm 0.71^{\# \#}$ & $0.77 \pm 0.65$ \\
Performance & GMC & $4.56 \pm 1.19$ & $5.33 \pm 1.02^{* * *}$ & $0.29 \pm 0.12$ \\
& GMA & $2.54 \pm 0.39$ & $2.83 \pm 0.4^{* * *}$ & $0.29 \pm 0.24$ \\
\hline
\end{tabular}

Table 4. Average values and variances types of the performance of the three groups before and after learning.

\begin{tabular}{cccc}
\hline Methods & Before & After & $\Delta$ (Before-after) \\
\hline GMA & $2.54 \pm 0.39$ & $2.83 \pm 0.4^{* * *}$ & $29 \% \pm 0.12$ \\
GMSP & $2.85 \pm 0.3^{\# \#}$ & $3.14 \pm 0.3^{* * *}$ & $29 \% \pm 0.24$ \\
GMC & $2.83 \pm 0.36^{\# \#}$ & $3.23 \pm 0.32^{* * *}$ & $4 \% \pm 0.25^{\#+}$ \\
\hline
\end{tabular}


superiority of the profile of the post-test scores. On the other hand, comparing averages is clear progress in the different groups tested, ranging from $0.29 \%$ corresponding to a minimum rate improvement up to $0.4 \%$ characterizing the highest progress, which explains that the three groups showed significantly different improvements statistical resolutions averages and percentages, registered in all three groups allow to observe the improvements made by each of the three methods. And that each of the groups has improved very significantly. Similarly, various improvements recorded at the level of the effect (methods, learning or even at the level of the interaction method and learning) are in favor of the group teach by the method combined the performance in judo...). However, we can deduce that the results achieved at the level of progress significantly participate in improving the performance students which explains the new stadium of knowledge. These advances in performance differences are illustrated in Figure 1.

Figure 2 shows that the comparison of progress is very significantly different in performance between the three groups. Thus the order relation is: combined $>$ analytical method method $>$ method with situation problem.

The procedural attitude: The procedural attitude was appreciated across the three phases in judo, procedural attitudes concerning the preparation, execution and fall. The results shown in the table below from the procedural attitudes show that different statistical figures, at the level of the percentages of improvements are significantly different which is explained by the difference in the averages reflecting a rate ranging from $0.32 \%$ in the group whose learning is based on the analytical method up to $0.99 \%$ for learning with situation problem in standing judo who made significantly better progress. Similarly, these advances are at the origin of the effect of learning within each group study and the interaction between (method and learning) illustrated by $\mathrm{F}(1 ; 87)=$ 52.27 report which is significant at p \& lt; 0.001 at the level of learning and the $F(2 ; 87)=4.3$ report; $\mathrm{p}=0.017$ at the level of the interaction method and learning well, the analytical method has no significant difference at the level of the procedural attitude nor under the effect of the method or the effect of learning. We can deduce that the method applied for each group does not have an effect on the procedural attitude and that the progress

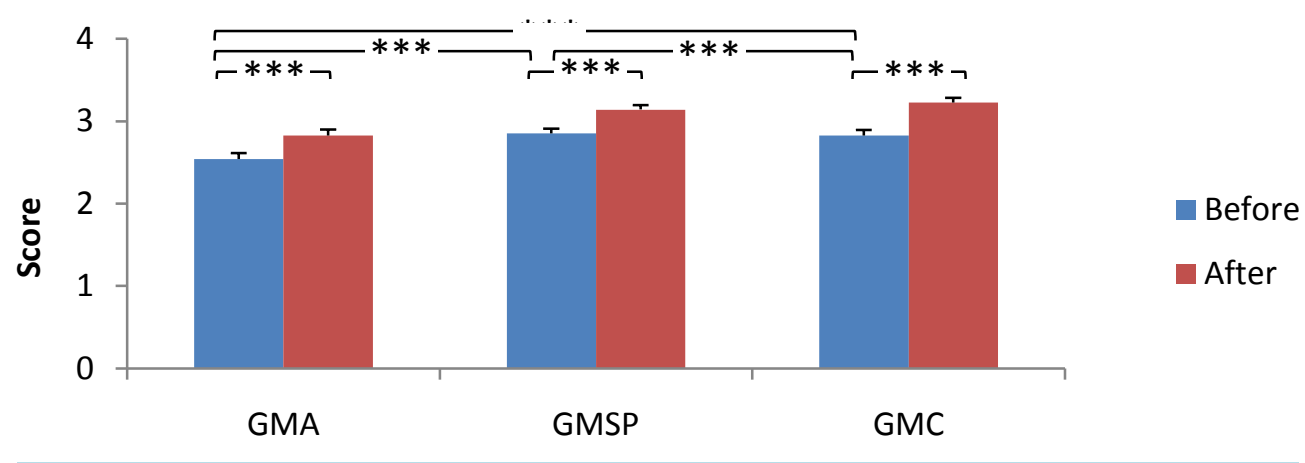

Figure 1. Evolution of the performance in judo under the effect of the method used in each of the three groups before and after training. * Significant difference at p \& lt; 0.05; " p \& lt; 0.01; p \& lt; 0.001 .

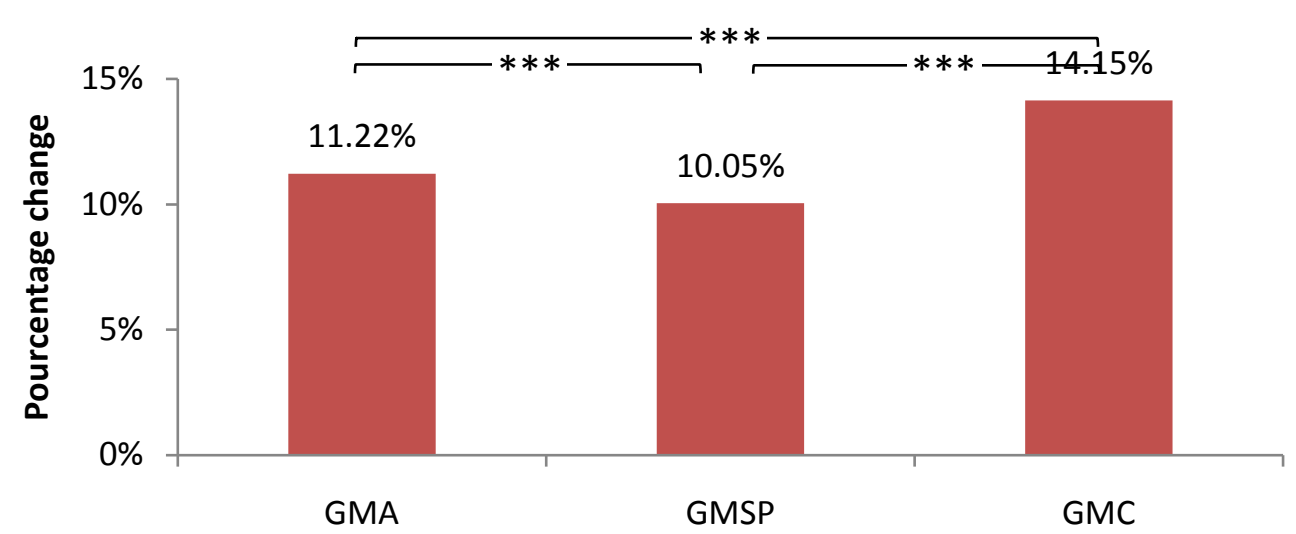

Figure 2. Percentage change $(\Delta \%)$ in the performance of the three groups. ${ }^{*}$ Significant difference at p \& lt; 0.05. 
illustrated by computing the ANOVA are under the effect of learning and its interaction with the method at the level of the two groups (with situation problem and combined) as "Table 5":

With regard to the "procedural Attitude", the ANOVA showed:

$\square$ a non significant 'Method' effect $[\mathrm{F}(2 ; 87)=2.72 ; \mathrm{p}=0.072] ; \mathrm{H} 2=0.059$

$\square$ a significant "learning” effect $[\mathrm{F}(1 ; 87)=52.27$; p \& 1t; 0.001]; H2 $=0.375$

$\square$ a significant "Method X learning" interaction $[\mathrm{F}(2 ; 87)=4.3 ; \mathrm{p}=0.017]$; H2 $=0.09$

This relationship can be observed on the basis of the percentages of improvements: $0.99 \%$ (situation problem method) \& gt; $0.77 \%$ (combined method) \& gt; $0.32 \%$ (analytical method). The comparison between the three groups on the basis of the " $\mathrm{X}$ " test, postest averages " $\mathrm{Y}$ " and the percentage of the improvements "purified, is shown in Figure 3".

However, although it has been demonstrated that the three groups have shown progress significantly different (significant F2), these differences are all significant? This apparent relationship is genuine and credible at all levels?

Comparison of improvements in the three groups taken two by two, allows us to conclude as to the meaning of each difference as "in Figure 4":

Anova shows that the only comparison of very significant progress in procedural attitude is noted between group learning using analytics and that learning is achieved by the method with situation problem. Thus, the apparent order relationship is checked as regards: method with situation problem \& gt; analytical method.

\section{Discussion}

We have tried in our present research to study the effect of learning (by status problem, analytical and combined)

Table 5. Average values and variances types of the procedural attitude of the three groups before and after learning.

\begin{tabular}{cccc}
\hline Methods & Before & After & $\Delta$ (Before-after) \\
\hline GMA & $4.48 \pm 0.93$ & $4.79 \pm 0.7$ & $0.32 \pm 1.25$ \\
GMSP & $4.61 \pm 0.63$ & $5.6 \pm 0.91^{* * *}$ & $0.99 \pm 0.71^{\# *}$ \\
GMC & $4.56 \pm 1.19$ & $5.33 \pm 1.02^{* * *}$ & $0.77 \pm 0.65$ \\
\hline
\end{tabular}

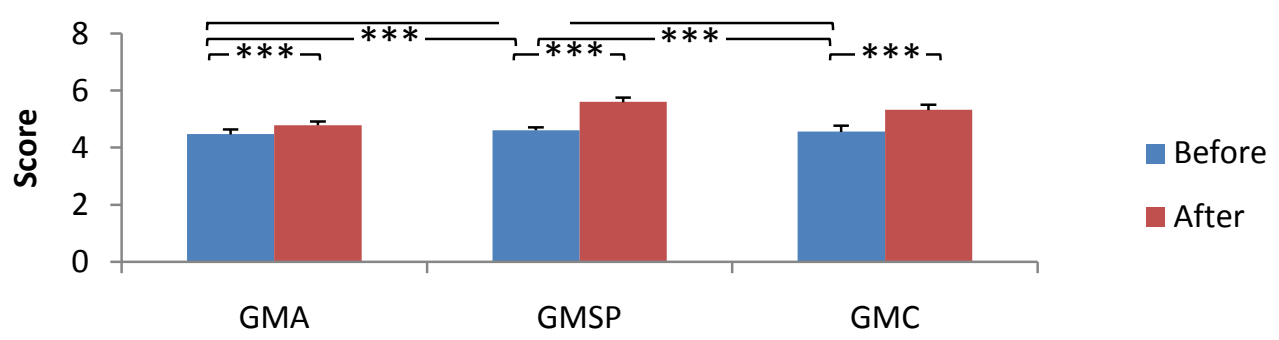

Figure 3. Evolution of procedural attitudes in judo under the effect of the method used in each of the three groups. * Significant difference at p \& lt; 0.05; p \& lt; 0.001.

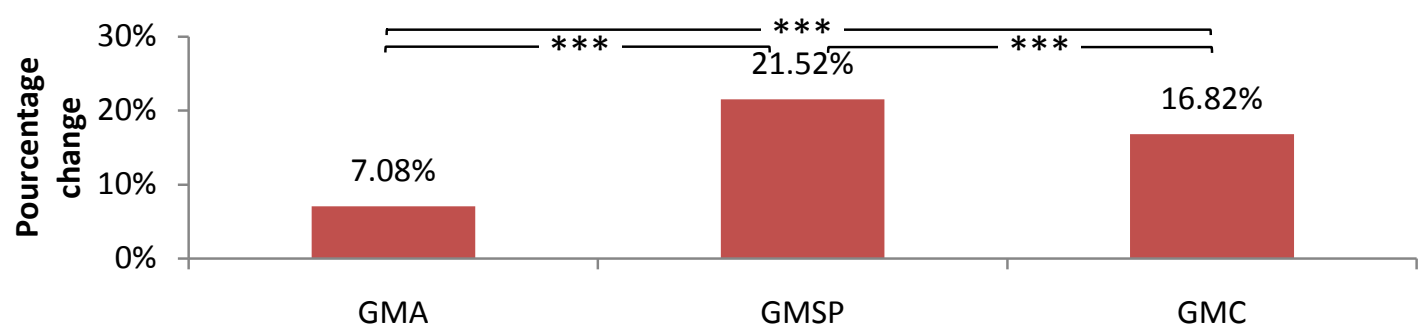

Figure 4. Percentage change $(\Delta \%)$ of the procedural attitude of the three groups. ${ }^{*}$ Significant difference at $\mathrm{p} \&$ lt; 0.05 . 
on knowledge in judo among students in the school promotion centre. In the application of these methods, we took into consideration the Organization instructional and epistemological activity judo following its internal logic, in order to highlight changes and changes in design and report to knowledge in the learner. To achieve these objectives, we resorted to an experiment conducted on three groups each practice judo by one of the three methods of learning. The results obtained show that there is a "effect method" teaching differentiated both on procedural attitudes and performance. However, learning (techniques, strategies, regulations) in judo in the classic relationship of teaching, the teacher speaks to the entire class and these are processes of transmission and acquisition of knowledge which are being implemented. But if the present teacher of knowledge, are we sure that they are also knowledge that students receive? Very often, the manner in which they receive and perceive them are information, that is, data that are for them little malleable, hardly reusable except to repeat them. This is often because, unlike school centres for the promotion of judo teachers, students do not have the same culture of accompaniment and contextualization of knowledge that they receive and are not yet sufficiently autonomous in their school operation; also, the mere transmission of knowledge is generally not sufficient so that they have ownership, even if the teacher of judo, as is often the case, made a double work of didactic transposition and pedagogical support to facilitate acquisitions. Our results validate our assumptions since the different teaching methods: analytical situation problem and combined have contributed, on the one hand, to a change on the psychomotor map (procedural attitudes and/or performance), and secondly, to a design change on the cognitive map (declarative and procedural knowledge) in judo. Regarding performance in judo, three teaching methods affect "method" significantly differentiated that emerges between the three experimental groups. However, the performance improvement is not directly related to changes in designs, made by different methods. The performance is thus manifested connected with declarative knowledge, or procedural knowledge. This allows us to infer that learning can occur both on the motor plan that perceptual and cognitive, without for all that there is a relationship of cause and effect on performance in particular. Also, the performance does not show necessarily conditioned in our case by the designs of the practitioners. However as said Meirieu (1990): "everyone would like to know, but not necessarily learn. We believe that physical activity, improve the designs cannot be sufficient alone to lead to progress in performance. Indeed, the engines acts require in addition to other variables such as factors of executions to produce better performance. May be should be a greater period of learning to enable performance factors to develop and that design changes can interact with these factors and thus produce a better performance. Also the heterogeneity of each group, learning each by a teaching method on all variables selected in our research learning can explained by the absence of relationship between improving attitudes and performance. In addition, share their characteristics, students react in the same way to the method with which they learn, that is why teacher should take account of what is common, what is different in each student and create conditions of learning suited to students to give maximum efficiency, it is in this sense that we speak of differentiated instruction. This converges with the ideas of Famose (1996), which shows that progress in motor performance continues for very long periods of time and that each particular level of performance to suggest that the skill is fully acquired is an arbitrary limit that can constantly evolve. The author adds that intellectual or verbal skills, in the field of sport, is acquired much more quickly than motor skills. Referring on the experiments of Thomas and French. The research of these authors showed that in sports, a procedural, declarative knowledge and motor skills rich and well-organized basis was essential to become an expert. They also showed that the first two types of knowledge essentially concerned the quality of decision-making, while the latter the quality of execution. Famose still reported using the experiences of Thomas, French and McPerson (French \& Thomas, 1987; McPherson and Thomas, 1991), the first two types of knowledge are learned more quickly than the last and that the first two have no connection with the acquisition of the last.

\section{Conclusion}

To further this research, a large number of learning theorists, ranging from the perspective of cognitive psychology described in addition the three types of knowledge, another category of knowledge that they have called strategic knowledge or cognitive strategies. In numerous studies on learning and problem solving, it was shown repeatedly that learners bring to new tasks not only performance and procedural attitudes and previously learned motor skills, but also some skills about when and how to use them. On the one hand, it focused on the development of declarative and procedural knowledge to identify their correlation with the performance in judo. On the other hand, it focused on the search for strategic knowledge that makes a student able to exert a degree of con- 
trol on any processes involved in the mental operations to be careful, to perceive, to memorize, to remember and to decide. They make the learners in the judo promotion centers able to choose, at the appropriate time, intellectual skills, declarative and procedural knowledge and motor skills that they will use to build their learning, remember and solve the problem.

\section{References}

Amade-Escot, C. (1989). EPS Teaching Strategies: Content Offered, Design of Learning and Perspectives of Differentiation. In: Methodology and Didactics of Physical Education and Sports. Documents Compiled by Bui-Xuan. AFRAPS (STAPS), Clermont-Ferrand, 119-130. http://www.recherches-en-education.net/IMG/pdf/REE-no19.pdf

Astolfi, J.-P. (1997). The Error, a Tool for Teaching. Paris: ESF. https://ec56229aec51f1baff1d185c3068e22352c56024573e929788ff.ssl.cf1.rackcdn.com/attachments/original/1/3/3/00261 6133.pdf

Ausubel, D. P. (1968). Educational Psychology: A Cognitive View. Holt: Rinehart et Winston. http://www.thenhier.ca/en/node/464

Baudot, G. et al. (1975). Judo Superior, Home Judoka, Paris, France, (5 Volumes). HTTPS://WWW.GOOGLE.TN/URL?SA=T\&RCT=J\&Q=\&ESRC=S\&SOURCE=WEB\&CD=1\&CAD=RJA\&UACT=8 \&VED=0AHUKEWJXM_TWQPOAHUEXBOKHDQBCNYQFGGZMAA\&URL=HTTP\%3A\%2F\%2FWWW.REVUE -EPS.COM\%2FFR\%2FJUDO-MEMENTO-CPS-FSGT-PAR-JEAN-PIERRE-ADAMI-ET-GERARD-COUTURIER A-8 962-PDF_DL.HTML\&USG=AFQJCNHZFWBT0CJZAYUY-E5AG5JCS4I3JA\&BVM=BV.128617741,D.BGS

Bresciani, T. (1984). A Cycle of Judo at the College Journal EP \& S No. 186. http://www.revue-eps.com/index.php?lg=fr\&id_nav=105\&debut=60

Bresciani, T. et al. (1963). The New Palgrave Dictionary of Economics (2nd ed.). In S. N. Durlauf, \& L. E. Blume (Eds.), Palgrave Macmillan, The New Palgrave Dictionary of Economics Online. Palgrave Macmillan.

http://www.treccani.it/enciclopedia/costantino-brescianiturroni_(Il_Contributo_italiano_alla_storia_del_Pensiero:_Econo $\underline{\text { mia) }}$

Carnus, M.-F. (2007) The "Researcher Effect" in the Observation of the Teaching Practices: Between Rationality and Subjectivity. Education, Université Paul Sabatier Toulouse Mirail-Toulouse. http://www.congresintaref.org/actes pdf/AREF2007 Marie-France CARNUS 193.pdf

Cauzinille-Marmèche, E. (1996). The Effect of Multipresentation: Highlighting in the Resolution of an Issue of Proportionality. Journal of Psychology of Education, $I$.

http://turing.scedu.umontreal.ca/gdm/documents/ActesGDM2011.pdf

Cazorla, G. (1989). The Assessment of Capacity Engines of the Route of a Concept A the Development of a Tool. Reviewed French of Pedagogy, 89, 15-22.

http://ife.ens-lyon.fr/publications/edition-electronique/revue-francaise-de-pedagogie/INRP_RF089_3.pdf

Cornu, L., \& Vergniaux (1992). Didactics in Questions. Paris: Hachette Education.

https://books.google.tn/books?id=qQE1YRW7HtkC\&pg=PA664\&lpg=PA664\&dq=CORNU,+L.+et+VERGNIOUX,+A.+ (+1992).+Les+didactiques+en+questions.+Paris:+Hachette.\&source=bl\&ots=RWpY7V5ksn\&sig=lUWsGRflVknzvfkMD JAMcS80uCg\&hl=fr\&sa=X\&ved=0ahUKEwjJnI7_2ubMAhUDSRoKHY5eCZ8Q6AEIITAB\#v=onepage\&q=CORNU\% 2C\%20L.\%20et\%20VERGNIOUX\%2C\%20A.\%20(\%201992).\%20Les\%20didactiques\%20en\%20questions.\%20Paris\%3 A\%20Hachette.\&f=false

Famose, J. P. (1988). Skills and Acquisition of Motor Skills. In J.-P. Famose, \& M. Durand (Eds.), Skills and Motor Performance. Paris: Editions Revised EPS. http://f3.quomodo.com/78D73CA0/uploads/21/aptitudes-1988.pdf

French, C., \& Thomas, F. (1987). The Game and the Group Games at the School. By Boeck Upper Ramazon France. https://books.google.tn/books?id=z0IpAwAAQBAJ\&pg=PA24\&lpg=PA24\&dq=Thomas+et+French+connaissances+proc\% C3\%A9drales+1987\&source=bl\&ots=iI7l3GvNY3\&sig=rBCrM94i74yqoiA09Na5C8owrLY\&hl=fr\&sa=X\&ved=0ahUKE witrY3oifMAhVMBBoKHXtZBiwQ6AEIGjAA\#v=onepage\&q=Thomas\%20et\%20French\%20connaissances\%20proc\%C3 \%A9durales\%201987\&f=false

Guthrie, E. R. (1957). The Psychology of Learning. New York: Harper. https://www.google.tn/url?sa=t\&rct=j\&q=\&esrc=s\&source=web\&cd=4\&cad=rja\&uact=8\&ved=0ahUKEwjHiO6v--bMA hWDtRoKHf6KDo4QFggtMAM\&url=http\%3A\%2F\%2Fnicolasblazy.free.fr\%2FEcrit_2_Fiches_files\%2FFiches $\% 2520 \mathrm{H}$ abiletes\%2520motrices.doc\&usg=AFQjCNFaDgZY1Kn9_kKZ7rBi029viWqLWg\&bvm=bv.122448493,d.d24

Herbrard, A. (1986). The EPS, Reflection and Prospects Review Co-Publications STAPS and ED Income in EPS. http://www.culturestaps.com/site_g000108.pdf

Inogai, T. et al. (1985). Practice Judo Inogaitadao. Amphora. http://www.docs-engine.com/pdf/1/judo.html 
Inogai, T., \& Habersetzer, R. (2002). Judo pratique: Du débutant à la ceinture noire. Amphora. http://www.abebooks.fr/judo-pratique-d\%C3\%A9butant-ceinture-noire-Inogai/18817837055/bd

Inokuma, I., \& Sato, N. (1986). Best Judo. Tokyo: Kodansha International. http://www.amazon.com/Best-Judo-Illustrated-Japanese-Classics/dp/0870117866

Janicot (1985). Judo of the 15/17 Years Practice and Training. Review EP \& S No. 195. http://www.revue-eps.com/index.php?lg=fr\&id_nav=105\&debut=60

Jonnaert, P. (2008). The Concept of Didactic: A Lexicometric Illustrative Study of a Corpus of Definitions. https://cudc.uqam.ca/upload/files/ORE17_concept\%20didactique.pdf

Loizon, D. et al. (2004). Analysis of Teaching Practices. Management Practices Declared by Professors from Judo. E-Journal (eJRIEPS), 5, 63-85.

http://www.issepks.rnu.tn/fileadmin/templates/Fcad/Analyse_des_pratiques_d_enseignement_du_judo_en_EPS.pdf

Malcuit, G., \& Pomerleau, A. (1977) Terminology in Conditioning and Learning. Montreal: PUQ. http://collections.banq.qc.ca/ark:/52327/bs1761948

Margnes, E., Loizon, D., \& Terrisse, A. (2008). Meaning of the Didactic Staged for Debutant in Judo in the Initial Training in STAPS.

https://hal-univ-bourgogne.archives-ouvertes.fr/hal-00562130/file/Sens_des_mises_en_scA_ne_didactiques_pour_le_dA_ butant_en_Judo_dans_la_formation.pdf

Marsenach, J., \& Amade-Escot, C. (1993). The Directions of Research in the Teaching of Physical Education and Sport. Revue Française de Pédagogie, 103, 33-41.

http://ife.ens-lyon.fr/publications/edition-electronique/revue-francaise-de-pedagogie/INRP_RF103_3.pdf http://dx.doi.org/10.3406/rfp.1993.1295

Meirieu, P. (1990). Learn... What, but How. Paris: ESF. https://www.reseau-canope.fr/savoirscdi/fileadmin/fichiers auteurs/Metier/Cours/meirieu.pdf

Newell, A., \& Simon, H. A. (1972). Human Problem Solving. Englewood Cliffs: Prentice Hall. http://garfield.library.upenn.edu/classics1980/A1980KD04600001.pdf

Perrenoud, P. H. (1999). Ten New Skills to Teach. Invitation to Travel. Paris: ESF. http://www.unige.ch/fapse/SSE/teachers/perrenoud/php_main/Textes_1999.html

Richard, J. F. (1997) La Résolution de Problèmes. In M. Richelle, J. Shark, \& M. Robert (Eds), Experimental Psychology (pp. 523-574). Paris: PUF. http://fulltext.bdsp.ehesp.fr/Rsi/50/47.pdf

Richard, J. F. (1998). Mental Activities, Understand, Reason, Find Solutions. Paris: Armand Colin. https://books.google.tn/books/about/Les_activit\%C3\%A9s_mentales.html?id=7BObPAAACAAJ\&redir_esc=y

Roegiers, X., \& de Ketele, J.-M. (2000). A Pedagogy of Integration. Brussels-Paris: De BoeckUniversité. http://www.bief.be/index.php?s=no\&uid=148

Salgado, M. (2013). Performance: A Fundamental Dimension for the Evaluation of Companies and Organizations. https://halshs.archives-ouvertes.fr/hal-00842219/document

Terrisse, A. (1996). Analysis of the Didactic Transposition in Judo: Evolution of "Knowledge Fight" in the Teaching of Judo at the School through the Magazine EPS from 1950 to 1993. http://www.persee.fr/doc/rfp_0556-7807_1996_num_116_1_1192

Terrisse, A. (2000). Epistemology of Clinical Research in Combat Sports. In A. Terrisse (Ed.), Combat Sports and Martial Arts, State of the Art Research (pp. 95-108). Paris: La táctica deportiva y la toma de decisions. http://www3.udg.edu/publicacions/vell/electroniques/IV_Jornades_tactica_tecnica_esportiva/pdf/05_La\%20recherche_en didactique clinique.pdf

Vygotsky, L. (1985). Thought and Language. Paris: Editions Socials http://www.persee.fr/doc/rfp_0556-7807_1987_num_79_1_2421_t1_0098_0000_2

Zanone, P. G., \& Kelso, J. A. S. (1992). Evolution of Behavioral Attractors with Learning: Nonequilibrium Phase Transitions. Journal of Experimental Psychology: Human Perception and Performance, 18, 403-421. https://books.google.tn/books?id=zpjejiytkiIC\&pg=PA304\&lpg=PA304\&dq=Zanone+\%26+Kelso,+1992\&source=bl\&ots =-bjA_Ge39t\&sig=peU8yGxy4VuPoOkJUdeleA3CBs\&hl=fr\&sa=X\&ved=0ahUKEwiHit7X4ubMAhUFPxoKHYeqBMc Q6AEIRDAI\#v=onepage\&q=Zanone\%20\%26\%20Kelso\%2C\%201992\&f=false http://dx.doi.org/10.1037/0096-1523.18.2.403 


\section{Appendix}

Table A1. Observation grid for the assessment of the procedural attitude.

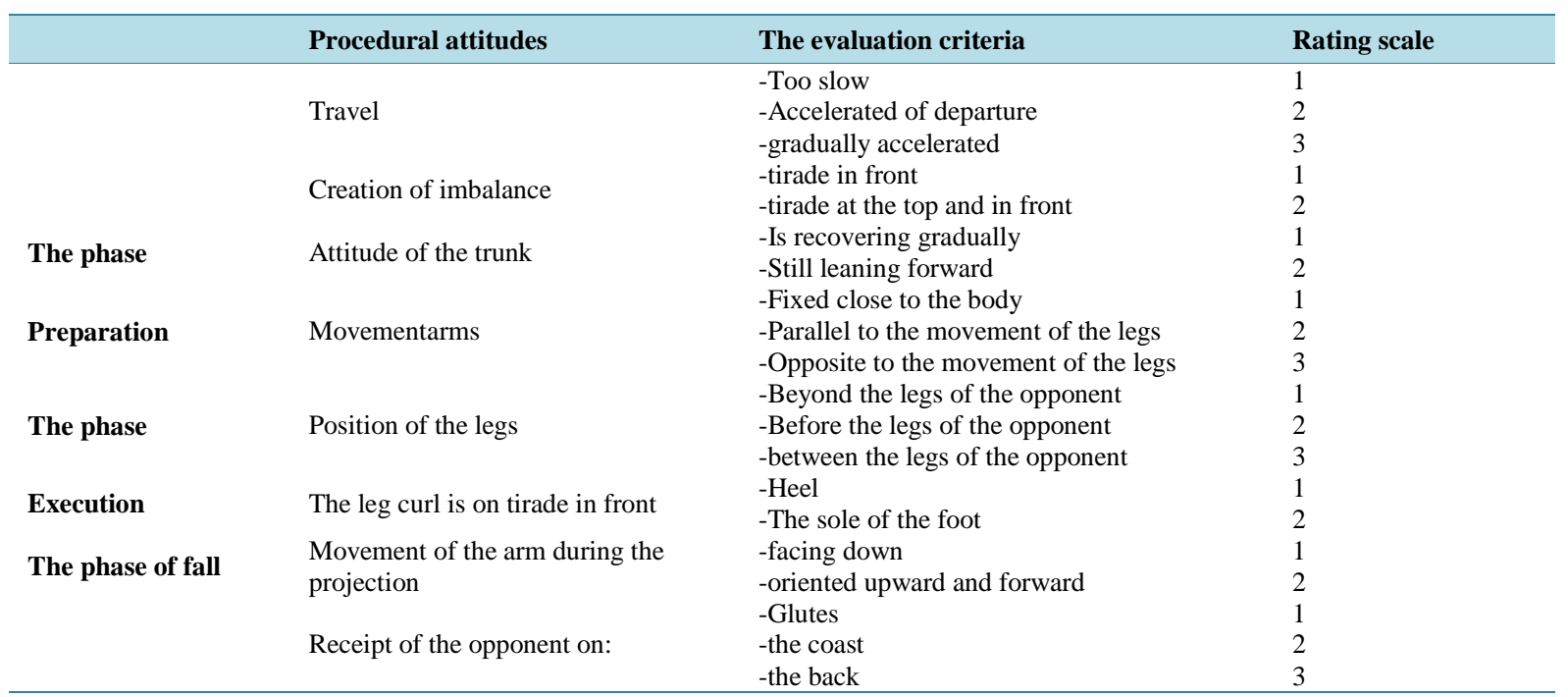

\section{Submit or recommend next manuscript to SCIRP and we will provide best service for you:}

Accepting pre-submission inquiries through Email, Facebook, LinkedIn, Twitter, etc.

A wide selection of journals (inclusive of 9 subjects, more than 200 journals)

Providing 24-hour high-quality service

User-friendly online submission system

Fair and swift peer-review system

Efficient typesetting and proofreading procedure

Display of the result of downloads and visits, as well as the number of cited articles

Maximum dissemination of your research work

Submit your manuscript at: http://papersubmission.scirp.org/ 